\title{
Bee and wasp stings in Deniyaya; a series of 322 cases
}

\section{E W R A Witharana'1, S K J Wijesinghe ${ }^{1}$, K S M Pradeepa'1, W A I P Karunaratne ${ }^{2}$, S Jayasinghe ${ }^{3}$}

(Index words: Hymenopterans, Apis dorsata, Vespa tropica, Ropalidia marginata, epidermal necrosis, anaphylaxis)

\begin{abstract}
Objectives To describe wasp and bee species that sting humans, analyse risk factors and clinical features.

Methods A prospective observational study was conducted on patients presenting to Base Hospital Deniyaya with suspected bee and wasp stings from 2011 to 2013 . Data were gathered using a questionnaire and specimens of offending insects collected for identification. When the insect specimen was unavailable, identification was made by the victim selecting (without prompting) from several dead specimens presented by the first author.
\end{abstract}

Results There were 322 patients (mean age: 42.5 years, SD: 15.1, 173 [53.7\%] males). Insects were brought by $55(17 \%)$ and $267(83 \%)$ were identified using specimens. All occurred during day-time, $142(44.1 \%)$ during August and September, and 200 victims (62\%) were tea plantation workers. Majority $(78.9 \%)$ reported a localized painful self-limiting swelling without systemic features and 15 $(4.6 \%)$ developed anaphylactic shock. None died. Five specimens were available from those in anaphylactic shock (four Apis dorsata, one Ropalidia marginata). Vespa tropica stinging caused a characteristic skin lesion. Of the 55 specimens, 46 (83.6\%) were Apis dorsata (Giant honey-bee, "Bambara"), 8 (14.5\%) Vespa tropica (Greater banded hornet, "Debara") and one Ropalidia marginata (Paper wasp, "Kaladuruwa").

Conclusions Only three hymenoptera species stings were reported. Risk factors included day-time outdoor activities, occupation (tea plantation workers) and period of year. The latter may be due to pollen season when the insects are found in abundance. Only $4.6 \%$ of the patients developed anaphylactic shock. Vespa tropica stings led to a unique skin lesion.

Ceylon Medical Journal 2015; 60: 5-9

\section{Introduction}

Worldwide fatal stings from insects probably result in an appreciable number of deaths. United States report 40 deaths due to insect stings and Australia, 2-3 deaths annually $[1,2]$. Globally Emergency Department visits due to allergy and systemic envenomation after Hymenoptera sting are not uncommon [3].

Hymenopterans are insects broadly categorised into three families; Apidae (honeybees, bumblebees), Vespidae (hornets, wasps, and yellow jackets) and Formicidae (fire ants) [4]. In Sri Lanka, there are three reported species of wasps belonging to the genus Vespa namely $V$. affinis (Linnaeus), V. tropica (Linnaeus) and V. mandarinia (Smith) [5]. Old world paper wasp Ropalidia marginata is found in the Indian peninsula [6]. The domesticated Asian honeybee, Apis cerana ("Meemessa"), the feral giant honeybee, Apis dorsata ("Bambara"), the feral dwarf honeybee Apis florae ("Daduwel mee") and the stingless bee, Trigonairidipennis ("Kaneyya messa") are common honeybees found in rural and urban areas in Sri Lanka [7].

Effects of Hymenoptera sting can range from irritation to severe form of anaphylactic shock [1]. Multi organ failure, rhabdomyolysis, electrocardiographic changes, acute kidney injury and myocardial infarction are well known complications of mass envenomation due to hymenoptera sting [8-11]. There are reports of acute kidney injury, myocardial infarction, severe anaphylaxis and bowel gangrene after giant Asian honeybee or wasp sting in Sri Lanka [8,12-14].

Epidemiological and clinical aspects of Hymenoptera stings are not well known in Sri Lanka. Many health care workers in rural areas lack in-depth knowledge about different species of Hymenopterans and clinical features resulting from stings.

Sri Lanka has extensive biodiversity with natural green vegetation ranging from low land rain forests to dry zone forests. Deniyaya is a rural area located close to the world heritage Sinharaja tropical rain forest. It is situated at high altitude and has many tea plantations [15]. Therefore, significant numbers of patients with insect attacks are admitted to the Deniyaya hospital for emergency treatment.

Female hymenopterans have a stinging apparatus (stinger) which is a modified ovipositor located at the tip

${ }^{1}$ Base Hospital, Deniyaya, ${ }^{2}$ Department of Zoology, University of Peradeniya and ${ }^{3}$ Department of Clinical Medicine, University of Colombo, Sri Lanka.

Correspondence: EWRAW, e-mail: <elapathawitharana@gmail.com>. Received 16 September and revised version accepted 7 November 2014. Competing interests: none declared. 
of their abdomen and is associated with a venom gland [4]. The stinging apparatus is used as defence if the insect is disturbed. The stinger is detached from the body after a single sting by the honeybee and it dies thereafter. But a single wasp is capable of stinging multiple times as the stinger is not separated from the body after sting. This finding is useful to differentiate honeybee from wasp as wasps do not leave the stinger on the victim's skin [14]. Venom glands of hymenopterans produce a variety of toxic substances including active amines (serotonin, histamine, tyramine, catecholamines), wasp kinins (similar in composition to bradykinins) and histaminereleasing peptides [9].

The aim of this study was to identify hymenopterans up to species level and characterise common risk factors and clinical features following different hymenoptera sting in Deniyaya, a rural area in Sri Lanka.

\section{Methods}

A prospective observational study was conducted at Deniyaya Base Hospital, Sri Lanka. Medical officers, collected data from patients admitted with stings of either bees or wasps during the two year period from September 2011 to August 2013. Only patients who confidently identified the insect during the incident as honeybees or wasp were included in the study and patients stung by insects other than bees and wasps were excluded. Specimens of the offending insect were collected for identification. In instances where the insect was not available, patient was asked to identify the insect from a series of dead specimens of stinging hymenopterans presented by the first author. All patients completed a questionnaire that gathered information on sociodemographic aspects, context and time of sting, features of offending insect, symptoms and treatment. Written informed consent was obtained from every patient.

Detailed clinical history was obtained and all patients were examined to gather information regarding incident, identification of insect, allergic manifestations, vital signs, anaphylaxis and signs and symptoms of organ dysfunction. All patients were observed in the ward and blood pressure, pulse, respiratory rate and urine output were monitored. The investigators looked for presence of a stinger on the skin. If stingers were present they were immediately removed and the numbers were counted. Information was obtained whether the stinger was present on the skin because sometimes the stinger was removed before arrival at the hospital. The presence of a stinger is helped to differentiate honeybees from wasps. Reduced blood pressure (systolic blood pressure of less than 90 $\mathrm{mm} \mathrm{Hg}$ or $>30 \%$ decrease from that person's baseline after exposure to known allergen) was considered as anaphylaxis in our patients [16]. Data entry and statistical analysis were done using Microsoft EXCEL.

\section{Results}

A total of 11254 patients were admitted to medical wards during the study period and 322 of them were stung by wasps or honeybees. There were $173(53.7 \%)$ males and $149(46.3 \%)$ females. The mean age was 42.5 years, $(\mathrm{SD}=15.1)$. Two hundred and thirty six $(73 \%)$ of victims were aged 20-60 years. Ethnicity was 164 (50.9\%) Sinhalese, 156 (48.4\%) Tamils and 2 (0.7\%) Muslims.

Thirty patients $(9.3 \%)$ were stung by wasps and $292(90.7 \%)$ were stung by honeybees. In the 30 patients who identified hymenopterans as wasps (29 Vespa and one Ropalidia marginata) stingers were not found on the victim's skin. Also the victims of wasp sting could identify wasp as Vespa as they are bigger than bees and by the presence of yellow bands on the abdomen of the insect. One patient identified the offending insect as Ropalidia marginata and this was confirmed by identifying the specimen of insect. In the 292 patients who were victims of honeybee sting (feral giant Asian honeybee, Apis dorsata, the "Bambara") stingers were embedded in the skin. All patients with stingers on the skin were stung by Apis dorsata (feral giant honeybee). This was easily identifiable as it is the largest (17-20 $\mathrm{mm}$ in length) and the most aggressive honey bee in the country. Apis cerana ("Mee messa"), the feral dwarf honeybee Apis florae ("Daduwel mee") were excluded as they were smaller in size compared to feral giant honeybee (Apis dorsata).

Species level identification was made in 55 specimens brought by the patients. Of them 46 were Apis dorsata, eight were Vespa tropica and one was Ropalidia marginata, identification was done according to characteristic morphological features (Figure 1). Sinhala names for Apis dorsata, Vespa tropica, and Ropalidia marginata are "Bambara", "Debara" and "Kaladuruwa" respectively. A worker giant Asian honeybee is approximately $17-20 \mathrm{~mm}$ long and has a hair covered body [14]. The length of Vespa tropica female is $19-30 \mathrm{~mm}$ with a large, stout body covered with strong, stiff hairs and the second gastraltergite (2nd dorsal shield of the abdomen) is yellow with a slight brown area basally [17].

During the 2 year study period from 2011 to 2013 majority of cases were reported at the end of the year with a peak (44.1\%) in August and September. The highest number of cases $(n=49)$ was reported in August 2013, whereas lowest number $(3.7 \%)$ of patients was reported from January to March each year. During this period the number did not exceed six per month (Figure 2).

Interestingly, all cases were reported between 6.00 am to $7.00 \mathrm{pm}$, indicating stinging occurred during day time. Peak incidence was $(n=62)$ from $11.00 \mathrm{am}-12.00$ noon.

Two hundred $(62 \%)$ were stung by honeybees or wasps while working in the tea plantation. Eighty eight were stung while walking along roads or foot paths, four people while indoors and another two when trying to remove a wasp nest (Table 1).

Ceylon Medical Journal 

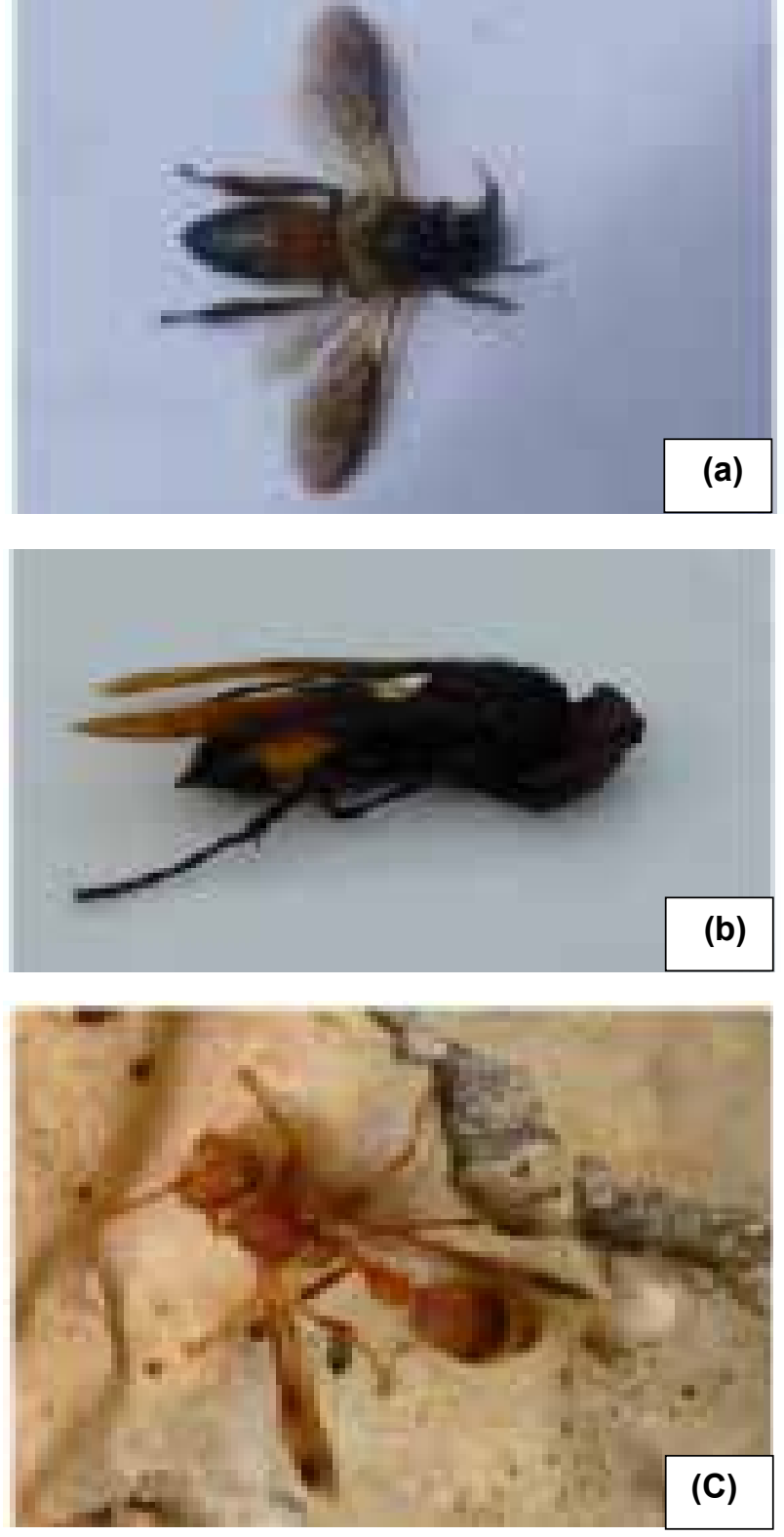

Figure 1. Stinging Hymenopterans reported in Deniyaya, (a) Apis dorsata, (b) Vespa tropica and (c) Ropalidia marginata.

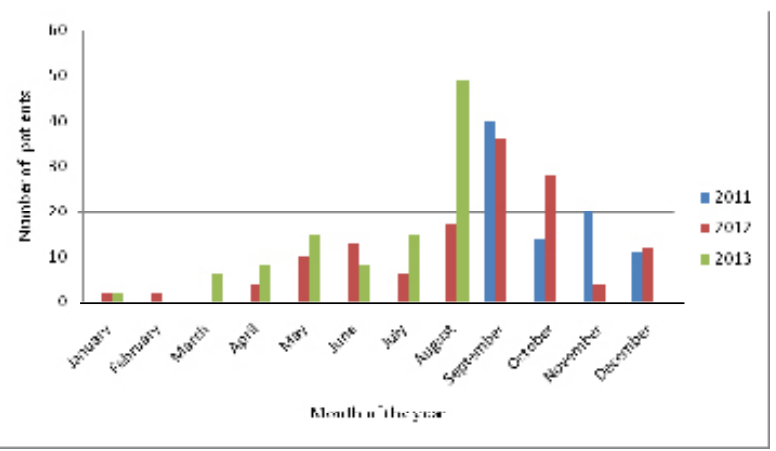

Figure 2. Hymenoptera sting distribution according to the month of the year.
Table 1. Place where people were stung by honeybees and wasps

\begin{tabular}{lcccccc}
\hline Place & \multicolumn{2}{c}{ Bee sting } & \multicolumn{2}{c}{ Wasp sting } & \multicolumn{2}{c}{ Total } \\
& $n$ & $\%$ & $n$ & $\%$ & $n$ & $\%$ \\
\hline Working in & & & & & & \\
tea plantations & 184 & 63.0 & 16 & 53.3 & 200 & 62.1 \\
Gardening & 05 & 01.7 & 04 & 13.3 & 9 & 2.8 \\
Walking & 83 & 28.4 & 05 & 16.7 & 88 & 27.3 \\
Indoors & 04 & 01.4 & 00 & 00 & 04 & 1.2 \\
Other & 16 & 05.5 & 05 & 16.7 & 21 & 6.6 \\
\hline
\end{tabular}

Seventeen had used permute when they were stung by hymenopterans. Thirty $(9.3 \%)$ patients had mass envenomation that could have lead to multi-organ failure (i.e. carried more than 100 stings per person), but none developed these complications. All patients with more than 100 stings were stung by bees. Majority with honeybee stings $(66.1 \%)$ had more than 10 stings per person whereas patients stung by wasps had less than 10 stings per person.

All patients developed pain over the stinging site and $79.2 \%$ had swelling over the site of the sting. Facial puffiness was reported in $37.3 \%$ and nausea or vomiting in $16.5 \%$. Bronchospasms $(2.5 \%)$, change of voice $(0.6 \%)$, throat pain $(0.9 \%)$ and abdominal pain $(2.1 \%)$ were reported in lesser number of patients. These symptoms were not reported in the patients stung by wasps (Table 2).

Table 2. Clinical features due to bee and wasp stings

\begin{tabular}{lcll}
\hline Clinical features & $\begin{array}{c}\text { Bee sting } \\
n(\%)\end{array}$ & $\begin{array}{c}\text { Wasp sting } \\
n(\%)\end{array}$ & $\begin{array}{c}\text { Total } \\
n(\%)\end{array}$ \\
\hline Pain & $292(100)$ & $30(100)$ & $322(100)$ \\
Swelling & $229(78.4)$ & $26(86.7)$ & $255(79.2)$ \\
Facial puffiness & $113(38.7)$ & $07(23.3)$ & $120(37.3)$ \\
Nausea/vomiting & $48(16.4)$ & $05(16.7)$ & $53(16.5)$ \\
Throat pain & $03(1.0)$ & 00 & $03(0.9)$ \\
Change of voice & $02(0.7)$ & 00 & $02(0.6)$ \\
Bronchospasms & $08(2.7)$ & 00 & $08(2.5)$ \\
Abdominal pain & $07(2.3)$ & $03(10)$ & $07(2.1)$ \\
Anaphylaxis & $13(4.4)$ & $02(6.7)$ & $15(4.6)$ \\
\end{tabular}

Majority (78.9\%) had localized painful selflimiting swelling without systemic features. Fifteen (4.6\%) developed anaphylactic shock after exposure to Hymenoptera venom but none of them died. Thirteen $(4.5 \%)$ of those who developed anaphylaxis were stung by bees. 

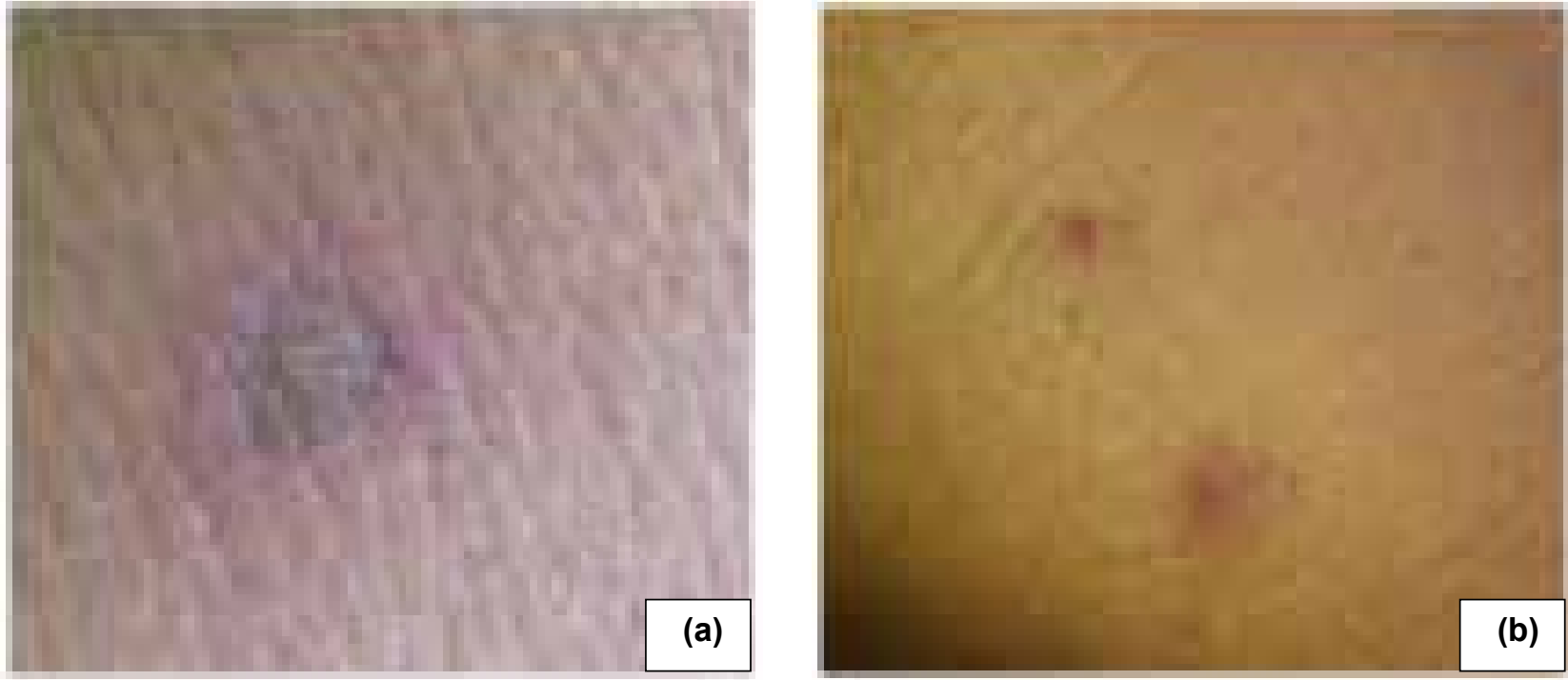

\section{Figure 3. (a) Characteristic skin lesion over the stinging site of Vespa tropica (b) Erythematous lesion over the stinging site of Apis dorsata.}

We observed a characteristic cutaneous lesion over the sting site of the wasp, Vespa tropica [18]. In bee stings (Apis dorsata), there was a stinger and some patients developed an erythematous lesion over the stinging site (Figure 3).

Two patients were transferred to a tertiary care hospital where more facilities were available. One patient developed a red eye after a single bee sting over the sclera and another with more than 1000 stings all over the body.

\section{Discussion}

Our study showed that $2.9 \%$ of medical ward admissions sought emergency treatment after wasp or bee stings at Base Hospital, Deniyaya. The reason may be that Deniyaya has tea plantations and forests with plenty of nesting sites for insects. Majority of victims of bee and wasp sting were aged 20-60 years which consists of the working population.

Majority of people were stung (62\%) when they were working in tea plantations. The area is abundant with tea plantations and according to 90 victims, both honeybees and wasps nest on tea bushes (28\%). Many people encroaching in the territorial range are stung when bees and wasps are provoked. A significant number of patients (29\%) were stung while they were walking on the road. Most (98.2\%) were stung when victims were engaged in outdoor activities. All cases were reported during day time from 6.00 am to $7.00 \mathrm{pm}$ indicating that bees and wasps of this area were active during day time.

Giant Asian Honeybees make their nest in an open area and thousands of bees hang from the nest. Once bees are disturbed, thousands of colony members leave the nest and attack intruders within their territorial range. Unlike honeybees, wasps (Vespa) build their nests enclosed, using paper like material and hence only few insects can be seen from outside. Therefore, mass envenomation may be common with stings by honeybees than wasps.

The highest number of patients presented during the period August to September whereas the lowest number patients were reported in January to March. The reason for this seasonal variation is not known though it may be related to periods when pollination is high. Rain fall and other human activities too could contribute.

Honeybees are attracted to specific colours and smells [19]. Only a few victims had used perfumes as most of villagers and farmers who rarely used perfumes. Some patients reported that nests of honeybees may be damaged and carnivorous birds (eagles or other birds) feed on pupa.

Clinical features varied from simple erythema to severe form of anaphylaxis. There is one previous study conducted in Anuradhapura District which describes Vespa affinis stings. According to this study 6.4\% developed anaphylaxis and most of the victims were agricultural workers [3]. Even though several species of honey bees and wasps have been reported in Sri Lanka, in Deniyaya area, hymenoptera strings were reported only of Asian giant honey bee (Apis dorsata), grater banded hornet (Vespa tropica) and paper wasp (Ropalidia marginata).

In conclusion, as significant number of patients $(3 \%$ of medical admissions) present with Hymenoptera stings and $4.6 \%$ developed anaphylaxis, the primary health care workers at hospitals located in high risk areas should have proper training and access to emergency medications. The characteristic lesion over stinging site of Vespa tropica described above may be used by physicians to identify the species when the specimen of the insect is not available. 


\section{Acknowledgements}

We thank Dr. Udaya Ranawaka, Department of Clinical Medicine, University of Kelaniya and Dr. Arosha Dissanayake, Department of Clinical Medicine, University of Ruhuna for their valuable advice and staff of Deniyaya Base Hospital for support in conducting this study.

\section{Declaration of Interest}

There are no conflicts of interest.

\section{References}

1. Gruchalla RS. Immunotherapy in allergy to insect stings in children. N Engl J Med 2004; 351: 707-9.

2. Warrell DA. Injuries, envenoming, poisoning and allergic reactions caused by animals. In: Warrell DA, et al. eds. Oxford Textbook of Medicine $5^{\text {th }}$ edition. 2010; Oxford. 1324-60.

3. Wijerathna BT, Rathnayake GK, Agampodi SK. Hornet stings presenting to a primary care hospital in Anuradhapura district in Sri Lanka. J Wildness \& Environmental Medicine 2014; 25: 122-6.

4. Casale TB, Burks AW. Hymenoptera-Sting Hypersensitivity. N Engl J Med 2014; 370: 1432-9.

5. Carpenter JM, Kojima J. Checklist of the species in the subfamily Vespinae (Insecta: Hymenoptera: Vespidae). Nat Hist Bull Ibaraki Univ 1997; 1: 51-92.

6. Gadagkar R, Gadgi M, Joshi NV, Mahabal AS. Observations on the natural history and population ecology of the social wasp Ropalidia marginata from peninsula India, Proceedings of the Indian Academy of Sciences (Animal Sciences), 1982, 91: 539-52.

7. Karunaratne WAIP, Edirisinghe JP. Keys to the common bees of Sri Lanka. J Natn Sci Foundation Sri Lanka 2008; 36: 69-89.

8. Kularatne SAM, Gawarammana IB, De Silva PHJG. Severe multiorgan dysfunction following multiple wasp (Vespa affinis) stings. Ceylon Med J 2003; 48: 146-7.

9. Vetter RS, Visscher PK, Camazine S. Mass envenomations by honey bees and wasps. West J Med 1999; 170: 223-7.
10. Rowe SF, Greer KE, Hodge RH. Electrocardiographic changes associated with multiple yellow jacket stings. South Med J 1979; 72: 483- 5

11. Levine HD. Acute myocardial infarction following wasp sting report of two cases and critical survey of the literature. Am Heart J 1976; 91: 365-74.

12. Gunasekera WTP, Mudduwa L, Lekamwasam S. Acute pigmented tubulopathy and interstitial nephritis following wasp sting. Galle Medical Journal 2008; 13: 1.

13. Gunasekara WDVN, Ratnatunga NVI, Abeygunawardena AS. Acute renal failure following multiple wasp bites. Sri Lanka Journal of Child Health 2007; 36: 67-8.

14. Budagoda BDSS, Kodikara KAS, Kularatne WKS, Mudiyanse RM, Edussuriya DH, Edirisinghe JP, Karunaratne IP, Weerakoon KGAD, Medagedara SC, Kularatne SAM. Giant Asian honeybee or Bambara stings causing myocardial infarction, bowel gangrene and fatal anaphylaxis in Sri Lanka: a case series. Asia Pac J Public Health 2010; 3: 586-8.

15. The National Atlas of Sri Lanka. 2nd ed. SriLanka: Department of Survey; 2007.

16. Sampson HA, Muñoz-Furlong A, Campbell RL, Adkinson NF, Bock SA, Branum A, et al. Second symposium on the definition and management of anaphylaxis: summary report - Second National Institute of Allergy and Infectious Disease/Food Allergy and Anaphylaxis Network symposium. J of Allergy Clin Immunol 2006; 117: 391-7.

17. Kumar PG, Srinivasan G. Taxonomic studies of hornet wasps (Hymenoptera: Vespidae) Vespa Linnaeus of India. Records of Zoological Survey of India 110(Part-2). 2010: 57-80.

18. Witharana EWRA, Wijesinghe SKJ, Pradeepa KSM, KarunaratneWAIP, Somarathna KM. A characteristic cutaneous lesion over the sting site of the wasp, Vespa tropica. Ceylon Med J 2014; 59: 24-5.

19. Diaz HD. Recognition, Management, and Prevention of Hymenopteran Stings and Allergic Reactions in Travellers. J Travel Med 2009; 16: 357-64. 